\title{
Ocular manifestations of dermal paraneoplastic syndromes
}

\author{
Alexander Zdebik ${ }^{1}$, Hanka Lantzsch ${ }^{1}$, Norbert Buhles ${ }^{1}$, Natalia Zdebik ${ }^{2}$ \\ ${ }^{1}$ Department and Clinic of Dermatology, Asklepios Nordseeklinik, Sylt/Westerland, Germany \\ 2Department and Clinic of Ophthalmology, Wroclaw Medical University, Wroclaw, Poland \\ Adv Dermatol Allergol 2020; XXXVII (3): 313-318 \\ DOI: https://doi.org/10.5114/ada.2020.96167
}

\begin{abstract}
Dermal paraneoplastic syndromes are non-malignant disorders, caused indirectly by the increase in growth factors or as immunological reactions, which lead to a variety of inflammatory, hyperkeratotic or proliferative skin reactions. They can occur as facultative or obligate paraneoplastic dermatoses, which are associated with oncological processes (solid tumours or hematologic diseases). The recognition of paraneoplastic skin disorders can accelerate proper diagnosis and determine better prognosis for the patient and is also important to clinicians because it is often the first symptom of life-threatening malignancies. Many of them may also cause ocular changes that can lead to serious complications including perforation of the eye bulb, vascular changes in the retina resulting in vision loss and demand multidisciplinary co-operation with an ophthalmologist. This manuscript is a review of the literature about eye disorders in association with dermal paraneoplastic syndromes.
\end{abstract}

Key words: skin, ocular manifestations, paraneoplastic syndromes, psoriasis, acanthosis nigricans, paraneoplastic pemphigus, Sweet syndrome.

\section{Genetics of psoriasis}

Paraneoplastic dermatoses are a heterogeneous group of diseases for today more than 50 skin disorders have been reported as potential signs of neoplasms [1]. This diverse group includes inherited syndromes with an increased incidence of systemic neoplasia associated with skin manifestations and a wide spectrum of proliferative and inflammatory disorders that have been reported in patients with malignancies. Curth's postulates are known to define a relation between an internal malignancy and a cutaneous disorder [2]. They include six statements and it is important to note that not all criteria must be met to postulate a relation between a skin disease and a malignancy. First, both the malignancy and the skin disease began simultaneously; second, development of a parallel course, which means that the cutaneous symptoms disappear during treatment and can return in case of recurrence or metastases of the malignancy; third, the skin lesion is not associated with a genetic syndrome; fourth, the relation between the skin disease and the malignancy is uniform, which means a specific tumour cell type or site is associated with a characteristic cutaneous eruption; fifth, a statistically significant association must exist between the malignancy and a specific cutaneous disease; and last the dermatosis is rare in the general population (Table 1 ). Skin lesions are indirectly induced by the tumour's release of growth factors, hormones or by an immunological, often T-cell mediated response to structures in the skin. Deposits of tumour antigen-antibody complexes on the basal membrane can also manifest as paraneoplastic phenomena [3]. Characteristic for paraneoplastic syndromes is that neoplastic cells are not present in the skin lesions.

Eye manifestations of the dermal paraneoplastic syndromes are not well known for the clinician, although a number of cases have already been reported. Ocular changes appear both on the anterior or posterior segment of the eye and can masquerade common disorders like chalazion [4], conjunctivitis [5], corneal ulcer, scleritis [6], episcleritis or uveitis [7]. Some of them can lead to serious complications, including blindness, like corneal perforation, panuveitis, occlusive vasculitis with retinal haemorrhages or optic nerve oedema [8, 9].

Address for correspondence: Dr Alexander Zdebik, Department and Clinic of Dermatology, Asklepios Nordseeklinik, Norderstraße 81, 25980 Sylt/Westerland, Germany, phone: +49 176 43767310, fax: +49 4651 841509, e-mail: zdebik@aol.com Received: 26.04.2018, accepted: 8.10.2018. 
Table 1. Curth's postulates 1. The malignancy and the skin disease both began
simultaneously

2. Development of a parallel course, which means that the cutaneous symptoms disappear during treatment and can return in case of recurrence or metastases of the malignancy

3. The skin lesion is not associated with a genetic syndrome

4. The relation between the skin disease and the malignancy is uniform, which means a specific tumour cell type or site is associated with a characteristic cutaneous eruption

5. A statistically significant association must exist between the malignancy and a specific cutaneous disease, and the dermatosis is rare in the general population

\section{Dermal paraneoplastic syndromes associated with eye disorders}

\section{Paraneoplastic pemphigus}

Multiple types of neoplasia have been associated with paraneoplastic pemphigus. The majority of them are lymphoproliferative malignancies. Other more or less malignant tumours, including poorly differentiated carcinomas, retroperitoneal non-Hodgkin lymphoma (reticulum cell sarcoma), Castleman's tumour, bronchogenic squamous cell carcinoma, gastric adenocarcinoma and endometrial adenocarcinoma and thymoma have been reported [3, 10, 11]. In 1990, Anhalt et al. established five criteria to define paraneoplastic pemphigus: 1. painful mucosal erosions and a polymorphous skin eruption, with papular lesions progressing to bullae and resulting in erosive lesions affecting the trunk, extremities, and palms and soles, associated with confirmed or occult neoplasm; 2. cutaneous histologic changes - intraepidermal acantholysis, keratinocyte necrosis, and vacuolar-interface dermatitis; 3. deposition of IgG and complement in the epidermal intercellular spaces, as well as granular-linear complement deposition along the epidermal basal membrane zone (direct immunofluorescence test); 4. serum auto-antibodies that bind the cell surface of epidermal skin cells and mucosal cells in a pattern typical of pemphigus, but in addition bind to simple, columnar, and transitional epithelia; 5. a complex of four proteins (190, 210, 230, 250 kD) immunoprecipitated from keratinocytes by these auto-antibodies [12].

Eye changes like conjunctival erosions, pseudomembranous conjunctivitis and relentless conjunctival scarring with symblepharon formation (comparable to the findings in ocular cicatricial pemphigoid) were described as the ocular manifestation of paraneoplastic pemphigus [10] (Table 2). Also paraneoplastic pemphigus with recurrent corneal melting, symblepharon and pterygium after 2 years of complete Castleman's tumour resection has been reported. Serum auto-antibodies remained detect- able for 2-4 years after surgery without recurrence of the tumour, suggesting that the immune reaction persisted [13]. Hyperaemic conjunctivitis in both eyes with large ulcerations on superior eyelids and marginal erosions on the inferior eyelids were also reported to be associated with paraneoplastic pemphigus [14]. In this case, conjunctival inflammation can be reduced by topical corticosteroids [14]. For eyelid ulceration, topical cyclosporine with dexamethasone and ofloxacin as an antibiotic has been described [14]. In another case, the authors presumed that paraneoplastic pemphigus caused ocular surface disease with small epithelial defects of the cornea, which eventually led to corneal melting and perforation [10]. Treatment in the case of corneal melting was conducted initially with frequent instillation of artificial tears and sodium hyaluronate. After perforation of the cornea and impending blindness, surgical procedures with a transplantation of an amniotic membrane graft has been proposed. If further melting of the cornea occurs, then a keratoplasty is recommended [10].

\section{Acanthosis nigricans}

Acanthosis nigricans occurs usually as a pigmented skin lesion over the neck, groin and axillar area or on the mucosal surfaces (particularly the oral mucosa). It has a variety of subtypes, including the hereditary type (presents during childhood and is usually benign and not associated with systemic disease), pseudoacanthosis nigricans that is associated with endocrine disorders (hyperinsulinemia, diabetes mellitus, thyroid disease, obesity and rare ACTH-releasing pituitary tumours), drug-induced acanthosis nigricans and the type which affects mostly elderly patients and is strongly associated with malignancy. Adenocarcinoma of the gastrointestinal tract (the most frequent), hepatic, oesophageal, bronchial carcinoma and breast cancer are the most common tumours associated with this paraneoplastic syndrome. Other tumours such as sarcomas, Hodgkin disease and lymphomas are rarer [15]. Conjunctival hyperaemia with fine papillary changes in both lid margins and tarsal conjunctiva, loss of the eyelashes and eyebrows, epiphora from occlusion of the canaliculi with papillomatous lesions and ectropion were reported as ocular findings in acanthosis nigricans $[15,16]$ (Table 2). For conjunctival hyperaemia, treatment with prednisolone $0.5 \%$ eye drops, hydrocortisone $1 \%$ eye ointment and artificial tear drops can be performed. In order to correct the ectropion, a diamond-shaped medial conjunctivoplasty can be performed [15].

\section{Sweet syndrome (acute febrile neutrophilic dermatosis)}

Sweet syndrome occurs as a papular rash or as indurated, painful erythematous plaques, located on the thorax, limbs and face. Alco extracutaneous manifestations 
Table 2. Dermal paraneoplastic syndromes

\begin{tabular}{|c|c|c|c|}
\hline $\begin{array}{l}\text { Dermal } \\
\text { paraneoplastic } \\
\text { syndromes }\end{array}$ & $\begin{array}{l}\text { Ocular manifestations on adnexae } \\
\text { and eye motility }\end{array}$ & $\begin{array}{c}\text { Ocular manifestation in the anterior } \\
\text { segment }\end{array}$ & $\begin{array}{l}\text { Ocular manifestation } \\
\text { in the posterior segment }\end{array}$ \\
\hline $\begin{array}{l}\text { Paraneoplastic } \\
\text { pemphigus }\end{array}$ & $\begin{array}{c}\text { Ulcerations on eyelids } \\
\text { Marginal erosions on the inferior } \\
\text { eyelids } \\
\text { Symblepharon }\end{array}$ & $\begin{array}{l}\text { Conjunctival erosions, } \\
\text { pseudomembranous conjunctivitis, } \\
\text { conjunctival scarring with } \\
\text { symblepharon formation, pterygium, } \\
\text { epithelial defects of the cornea, } \\
\text { corneal melting, corneal perforation }\end{array}$ & - \\
\hline $\begin{array}{l}\text { Acanthosis } \\
\text { nigricans }\end{array}$ & $\begin{array}{l}\text { Papillary changes on lid margins } \\
\text { and tarsal conjunctiva, loss of the } \\
\text { eyelashes and eyebrows, epiphora } \\
\text { from occlusion of the lacrimal ducts }\end{array}$ & Conjunctival hyperaemia & CARD14 \\
\hline $\begin{array}{l}\text { Sweet syndrome } \\
\text { (acute febrile } \\
\text { neutrophilic } \\
\text { dermatosis) }\end{array}$ & $\begin{array}{l}\text { Periorbital or orbital inflammation, } \\
\text { eruptions, eyelid inflammation with } \\
\text { vesicular lesions, dacryoadenitis }\end{array}$ & $\begin{array}{l}\text { Conjunctivitis, chemosis, episcleritis, } \\
\text { scleritis, nodular scleritis, } \\
\text { subconjunctival haemorrhage, } \\
\text { peripheral ulcerative keratitis, } \\
\text { keratitis, limbal nodules, iritis, } \\
\text { panuveitis, inflammatory glaucoma }\end{array}$ & $\begin{array}{l}\text { Choroiditis, retinal vasculitis, } \\
\text { occlusive vasculitis, panuveitis, } \\
\text { papillitis with secondary macular } \\
\text { oedema, disc oedema, glaucoma }\end{array}$ \\
\hline $\begin{array}{l}\text { Muir-Torre } \\
\text { syndrome }\end{array}$ & Sebaceous gland tumours on eyelids & - & - \\
\hline Gardner syndrome & $\begin{array}{c}\text { Orbital osteomas and soft tissue } \\
\text { tumours of the eyebrows and } \\
\text { eyelids }\end{array}$ & - & $\begin{array}{l}\text { Congenital hypertrophy of the } \\
\text { retinal pigment epithelium, } \\
\text { benign pigmented naevi, rarely } \\
\text { retinal invasion and formation } \\
\text { of a minute mushroom-shaped } \\
\text { tumour }\end{array}$ \\
\hline $\begin{array}{l}\text { Ataxia } \\
\text { telangiectasia }\end{array}$ & Disturbance in ocular motility & $\begin{array}{c}\text { Progressive conjunctival } \\
\text { telangiectasias (primarily visible in } \\
\text { the palpebral fissure) }\end{array}$ & - \\
\hline MEN 2B syndrome & $\begin{array}{l}\text { Eyelid thickening, neuromas, ptosis, } \\
\text { posterior blepharitis, decreased } \\
\text { basal tear production }\end{array}$ & $\begin{array}{l}\text { Subconjunctival neuromas, } \\
\text { conjunctival hyperaemia } \\
\text { with peripheral corneal } \\
\text { neovascularization, prominent } \\
\text { corneal nerves, rostral displacement } \\
\text { of cilia, poor pupillary dilatation } \\
\text { Development of perilimbal nodular } \\
\text { changes in association with the } \\
\text { neovascular corneal arcade and } \\
\text { prominent corneal nerves can be } \\
\text { a key distinguishing feature } \\
\text { of men type } 2 \mathrm{~b}\end{array}$ & - \\
\hline
\end{tabular}

including the eyes, kidneys, bone, liver, central nervous system, intestines, heart, mouth, muscles, spleen, and lungs can appear [6]. 20\% of cases appear as a paraneoplastic syndrome and from these $85 \%$ are related with haematological malignancies (mostly acute myeloid leukaemia). The other 15\% are associated with adenocarcinoma of the breast, upper genitourinary tract and upper intestinal tract [17]. There are three known clinical types: idiopathic, malignancy-associated or drug-induced. Diagnosis is based on various criteria [18]. Major criteria include abrupt onset of painful erythematous nodules or plaques and histopathological findings of dense neutrophilic infiltrate without evidence of leukocytoclastic vasculitis. Minor criteria are: fever $>38^{\circ} \mathrm{C}$, association with hematologic or visceral malignancy, inflammatory disease, pregnancy, appearance preceded by the upper respiratory tract infection, gastro-intestinal infection or vaccination, excellent response to treatment with systemic corticosteroids or potassium iodide, abnormalities in laboratory tests (three of four): erythrocyte sedimentation rate $>20 \mathrm{~mm} / \mathrm{h}$, high C-reactive protein, leukocytes $>8000 / \mu$ l with $>70 \%$ neutrophils. The presence of both one major criterion and two minor criteria is needed to establish the diagnosis of idiopathic Sweet syndrome and in paraneoplastic Sweet syndrome, an additional malignancy must precede, follow or appear simultaneously with the diagnosis. Drug-induced Sweet syndrome has other criteria to establish the diagnosis $[17,18]$. Ocu- 
lar involvement in Sweet syndrome is ranged from $4 \%$ to $72 \%$, with the appearance of conjunctivitis or episcleritis in most cases. Scleritis, subconjunctival haemorrhage, glaucoma (inflammatory glaucoma), orbital as well as periorbital and eyelid inflammation, eruptions, dacryoadenitis, limbal nodules, peripheral ulcerative keratitis, iritis, choroiditis, retinal vasculitis and occlusive vasculitis can also occur [6, 19-21] (Table 2). Severe bilateral chemosis as the first sign of recurrent Sweet syndrome in a patient with stable skin lesions and rapid clinical improvement after initiation of corticosteroid therapy were reported [19]. Another described case is bilateral panuveitis and papillitis with secondary macular oedema in the left eye and mildly increased T2 signal intensity in the right optic nerve on STIR images in MRI as a unique demonstration of Neuro-Sweet syndrome which usually presents with CNS involvement (meningitis or encephalitis) [21]. The age of patients with eye involvement are for women: from the third to the fifth decade and for men: from the fifth to the seventh decade. In half of the cases, manifestation is unilateral. Ocular symptoms appear simultaneously or several days after skin lesions [20], however, a case with Sweet syndrome in which the patient presented nodular scleritis and peripheral ulcerative keratitis during the dermatologically inactive period of the disease was described [6]. Treatment with fluorometholone $0.1 \%$, ofloxacin $0.3 \%$ and artificial tear eye drops 5 times a day together with oral fluocortolone has promising effects with immediate improvement within 2 days and resultant regression of nodular scleritis and peripheral keratitis after 7 days has been described [6].

Sweet syndrome and its potentially sight-threatening complications demand multidisciplinary co-operation.

\section{Inherited syndromes with an increased incidence of systemic neoplasias associated with skin manifestations}

Muir-Torre syndrome, Gardner syndrome, ataxia telangiectasia, MEN 2B are inherited disorders with an increased incidence of systemic neoplasias associated with skin and ocular manifestations. All of them except of ataxia telangiectasia, which is transmitted autosomally recessive disorder, are transmitted autosomally dominant disorder.

Muir-Torre syndrome is defined by the presence of internal malignancies of sebaceous gland tumours in the absence of other predisposing factors [22]. Sebaceous adenomas themselves are rare and benign sebaceous gland tumours can be found anywhere on the body. Due to the presence of meibomian glands and other sebaceous glands, the paraneoplastic syndrome has a predilection for the eyelids (Table 2). Also a case of Muir-Torre syndrome masquerading as chalazion has been reported [4]. Treatment for the sebaceous adenomas is promising solely with surgical excision of the lesions [23]. No local treatment shows satisfying results.

Gardner syndrome is one variant of familial adenomatous polyposis. Extracolonic manifestations present as osteomas, skin tumours, dental anomalies and desmoid tumour. Multiple or bilateral congenital hypertrophy of the retinal pigment epithelium is observed in this disorder and can be considered as a clinical disease marker [23]. The majority of lesions have a size of less than $0.5 \mathrm{DD}$, larger lesions of them have variable degrees of hypopigmentation, are usually ovoid to round shaped, can have a hypopigmented halo or tail and protrude near the posterior pole of the eye bulb. Small flat and hyperpigmented lesions are predominantly at the equator and fundus midperiphery [24]. The histologic changes discovered in the eyes in post-mortem examinations of patients with Gardner syndrome indicate an influence of the familial adenomatous polyposis gene on the retinal pigment epithelium. Congenital hypertrophy of the retinal pigment epithelium, benign pigmented naevi and other types of lesions that were most consistent with hamartomatous malformations of the retinal pigment epithelium feature cellular hypertrophy, hyperplasia, and rarely retinal invasion and formation of a minute mushroom-shaped tumour [25] (Table 2). Other uncommon lesions that can occur are orbital osteomas and soft tissue tumours of the eyebrows and eyelids [24]. No treatment has been described for the lesions on the retina.

Ataxia telangiectasia is a disorder characterized by early onset of progressive cerebellar ataxia, oculocutaneous telangiectasia, ocular motor apraxia, dysarthria and immunodeficiency that is associated with an increased susceptibility to haematological malignancies (lymphoma and leukaemia) and an increased prevalence of breast cancer [26]. Cutaneous involvement is common and presented as cutaneous telangiectasia, skin atrophy, café-au-lait spots and premature greying of hair and cutaneous granulomas. A case of multi-drug resistant rosacea in a child with ataxia telangiectasia also has been reported [27]. Eye changes occur as progressive conjunctival telangiectasias (primarily visible in the palpebral fissure, but in the elderly patient they can be also seen in the upper and lower conjunctival fornix) and disturbance in ocular motility [26] (Table 2).

MEN 2B is characterized by pheochromocytoma, multiple mucosal neuromas and medullary thyroid carcinoma, which is a potentially life-threatening condition. Eye disorders in MEN 2B syndrome present as a wide spectrum, including prominent corneal nerves, eyelid thickening, neuromas, ptosis and posterior blepharitis. Subconjunctival neuromas, conjunctival hyperaemia with peripheral corneal neovascularization, decreased basal tear production, rostral displacement of cilia, and poor pupillary dilatation $[28,29]$ (Table 2). Development of perilimbal nodular changes in association with the neo- 
vascular corneal arcade and prominent corneal nerves has been suggested to represent a key distinguishing feature of MEN type 2B (Table 2). Ocular manifestations can precede other systemic changes that enable recognition of MEN 2B in a premalignant stage, which makes them particularly important [29]. Treatment for conjunctival hyperaemia has been proposed with preservative-free lubricating drops and topical fluorometholone resulting in the alleviation of conjunctival hyperaemia and ocular symptoms [28]. In case of suspected staphylococcal hypersensitivity oral tetracyclines have been described as a treatment modality [28].

\section{Conclusions}

Contemporary patient management requires multidisciplinary co-operation between specialists and helps improve the quality of life, though one option is besides treatment of the underlying cancer and its paraneoplastic syndrome, the possibility of undergoing an oncological rehabilitation. The salutogenetic concept according to A. Antonovsky [30] renders rehabilitation as an important constituent of a holistically oriented tumour follow-up care [31].

Ocular manifestations of skin paraneoplastic syndromes should be known by clinicians because of their potentially sight-threatening complications that could be prevented early. Due to the fact that the ophthalmic symptoms may precede the appearance of changes on the skin or the development of malignancies, their knowledge enables prompt diagnosis of a life-threatening disease, thus improving the prognosis for the patient.

\section{Conflict of interest}

The authors declare no conflict of interest.

\section{References}

1. Da Silva JA, de Carvalho Mesquita K, de Souza Machado Igreja AC. Paraneoplastic cutaneous manifestations: concepts and updates. An Bras Dermatol 2013; 88: 9-22.

2. Thiers BH, Sahn RE, Callen JP. Cutaneous manifestations of internal malignancy. CA Camcer J Clin 2009; 59: 73-98.

3. Gießen-Jung C, Wollenberg A, Reinholz M. Paraneoplasien der Haut. Der Internist 2018; 59: 134-44.

4. Makrygiannis G, Vahdani K, Giasin O. Muir-Torre syndrome masquerading as chalazion. Ophtal Plast Reconstr Surg 2015; 31: 422-3.

5. Guillaume M, Benoist L, Cribier B, et al. Sweet syndrome presenting as resistant conjunctivitis. Cornea 2008; 27: 1189-90.

6. Bilgin AB, Tavas P, Turkoglu EB, et al. An uncommon ocular manifestation of Sweet syndrome: peripheral ulcerative keratitis and nodular scleritis. Arq Bras Oftalmol 2015; 78: 53-5.

7. Gottlieb CG, Mishra A, Belliveau D, et al. Ocular involvement in acute febrile neutrophilic dermatosis (Sweet syndrome): new cases and review of the literature. Surv Ophtalmol 2008; 53: 219-26.
8. Song WK, Bang D, Choi YJ, et al. Sudden visual loss due to occlusive venous vasculitis associated with Sweet syndrome. Arch Dermatol 2009; 145: 216-8.

9. Lobo AM, Stacy R, Cestari D, et al. Optic nerve involvement with panuveitis in Sweet syndrome. Ocul Immunol Inflamm 2011; 19: 167-70.

10. Beele H, Claerhout I, Kestelyn P, et al. Bilateral corneal melting in a patient with paraneoplastic pemphigus. Dermatology 2001; 202: 147-50.

11. Rutar T, Chan MF, Acharya NR, et al. Cicatrising conjunctivitis due to paraneoplastic pemphigoid. Br J Ophtalmol 2007; 91: 1562-3.

12. Anhalt GJ, Kim S, Stanley JR, et al. Paraneoplastic pemphigus: an autoimmune mucocutaneous disease associated with neoplasm. N Engl J Med 1990; 323: 1729-35.

13. Zhou S, Yuxin H, Lan, Y, et al. Recurrent corneal melting in the paraneoplastic pemphigus associated with Castleman's disease. BMC Ophthalmol 2016; 16: 106.

14. Piscopo R, Romano M, Maria AD, et al. Ocular onset of paraneoplastic pemphigus presenting as hyperemic conjunctivitis and massive bilateral eyelid ulceration: a case report and literature review. Ocul Immunol Inflamm 2018; 26: 265-8.

15. Tabandeh H, Gospal S, Teimory M, et al. Conjunctival involvement in malignancy-associated acanthosis nigricans. Eye 1993; 7: 648-51.

16. Gross EB, Mannis MJ, Brumley TB, et al. Eyelid involvement in acanthosis nigricans. Am J Ophtalmol 1993; 115: 42-5.

17. Cunquero-Tomás AJ, Ortiz-Salvador JM, Iranzo V, et al. Sweet syndrome as the leading symptom in the diagnosis of gastric cancer. Chin Clin Oncol 2018; 7: 11.

18. Villarreal-Villarreal CD, Ocampo-Candiani J, Villarreal Martínez A. Sweet syndrome: a review and update. Actas Dermosifiliogr 2016; 107: 369-78.

19. Michel G, Lhermitte B, Cribier B, et al. Sweet syndrome presenting as resistant conjunctivitis. Cornea 2008; 27: 1189-90.

20. Gottlieb CC, Mishra A, Belliveau D, et al. Ocular involvement in acute febrile neutrophilic dermatosis (Sweet syndrome): new cases and review of the literature. Surv Ophthalmol 2008; 53: 219-26.

21. Lobo AM, Stacy R, Cestari D, et al. Optic nerve involvement with panuveitis in sweet Syndrome. Ocul Immunol Inflamm 2011; 19: 167-70.

22. Jagan L, Zoroquiain P, Bravo-Filho V, et al. Sebaceous adenomas of the eyelid and Muir-Torre syndrome. Br J Ophthalmol 2015; 99: 909-13.

23. Laghmari M, Lezrek O. Congenital hypertrophy of the retinal pigment epithelium in Gardner's syndrome. Pan Afr Med J 2014; 19: 164

24. Traboulsi El. Ocular manifestations of familial adenomatous polyposis (Gardner syndrome). Ophthalmol Clin North Am 2005; 18: 163-6.

25. Traboulsi El, Murohy SF, de la Cruz ZC, et al. A clinicopathologic study of the eyes in familial adenomatous polyposis with extracolonic manifestations (Gardner's syndrome). Am J Ophthalmol 1990; 110: 550-61.

26. Riise R, Ygge J, Lindman C, et al. Ocular findings in Norwegian patients with ataxia-telangiectasia: a 5 year prospective cohort study. Acta Ophthalmol Scand 2007; 85: 557-62.

27. Cantarutti N, Claps A, Angelino G, et al. Multi-drugs resistant acne rosacea in a child affected by Ataxia-Telangiectasia: successful treatment with Isotretinoin. Ital J Pediatr 2015; 41: 23. 
28. Malhotra C, Jain AK, Thapa B, et al. In vivo confocal microscopic architecture of corneal nerves in a case of multiple endocrine neoplasia type $2 \mathrm{~b}$. Middle East Afr J Ophthalmol 2016; 23: 326-8.

29. Kreps EO, Van Herzeele I, Callewaert BL. Diagnosis of multiple endocrine neoplasia type $2 \mathrm{~B}$ and management of its ocular features. Ophthalmic Genet 2018; 39: 268-70.

30. Antonovsky A. Die salutogenetische Perspektive: Zu einer neuen Sicht von Gesundheit und Krankheit. 2. Aufl. Meducs 1981; 51-7.

31. Buhles N. Dermatoonkologie und Salutogenese. Rehabilitative Maßnahmen. Tumoren der Haut. Thieme-Verlag 2010; 689-90. 